rendering a supposed good piece of metal quite brittle and dangerous if trusted to do its ordinary duty, such accidents happening as a rule in cold weather? June 24 WILMot H. T. POWER

\section{Sagacity in Cats}

THE following facts are curious : I should be glad if any of your readers can inform me whether anything of the kird has been already noticed. I have a cat of half-Persian breed; she is about eight years old, and has always been remarkable for her aversion to strangers, more especially to children. If children have at any time come into the house where she was, she has invariably decamped and secreted herself. She never could bear to be handled or pulled about (which so many cats seem to enjoy) by anyone but by her master.

During the present year this cat has remained in Scotland; a few weeks ago my little boy went to reside in the house where the cat is at present. This boy is just at that age when children delight in pulling about everything they can get hold of : naturally a cat was a perfect godsend to him. After a few days the cat was seen to smell the child repeatedly; she seemed to be satisfied of his relationship, and since that time she follows him about the house (a thing which she never did to anyone but her master), rubs herself against him, and allows him to pull her tail and ears and draw her about by the legs.

Owens College, June 22

M. M. Pattison Muir

\section{OUR ASTRONOMICAL COLUMN}

LE VERRIER's TABLE' OF SATURN,-Vol, xii. of the Annales of the Observatory of Paris, containing, in addition to his Tables of Jupiter, the more extensive Tables of Saturn, was presented by M. Le Verrier to the Academy of Sciences on the 5 th of the present month. To insure, as M. Le Verrier has explained, their accurate and convenient application, the Tables of Saturn occupy two-thirds more space than those of Jupiter, or 278 and s7o pages respectively, though their general form and arrangement appears to be the same, and as those who have seen the Tribles of Jupiter will be aware, is materially different from the arrangement of the Tables of Mercury to Mars inclusive. The tables of Saturn represent exactly the observations from Bradley to the present day.

M. Le Verrier again mentioned that his theories of Uranus and Neptune were complete, and susceptible of being extended to an indefinite number of years. The comparison of the theories with observation is already sufficiently advanced to enable him to pronounce upon their satisfactory agreement.

36 OpHIUCHI.--It appears to have been somewhat hastily concluded that this star, so remarkable for its identity of proper motion, both as regards amount and direction with the distant 30 Scorpii, is also a binary system. So far the measures by no means bear out this inference, and unless they are affected with unusual errors it is not easy to explain thern. For comparison the following may be selected:-

\begin{tabular}{|c|c|c|c|c|c|c|c|c|}
\hline Hersch & 1 ar & So & ath & $1822 \cdot 52$ & Pos. & 227.4 & Dis. & $5^{\prime \prime}$ \\
\hline Hersch & & $\ldots$ & $\ldots$ & $1835^{\circ} 19$ & ,9 & 223.5 & $"$, & \\
\hline Dawes & $\ldots$ & $\ldots$ & $\ldots$ & 184.59 & ", & 219.3 & , & \\
\hline Jacob & $\ldots$ & $\ldots$ & $\ldots$ & 1846.21 & ," & 216.2 & ", & \\
\hline " & $\cdots$ & $\ldots$ & $\ldots$ & 1850.62 & , & $214^{\circ} 9$ & ", & \\
\hline B"rclo & $\cdots$ & $\cdots$ & $\ldots$ & 1854.07 & ", & 2144 & ", & \\
\hline Barcla & $\cdots$ & $\ldots$ & $\cdots$ & $\mathrm{I} 87 \mathrm{I} \cdot 5 \mathrm{I}$ & ", & 210.6 & ", & \\
\hline
\end{tabular}

It might be supposed from these measures, that while the angle has been slowly retrograding between the years 1822 and $187 \mathrm{I}$, the distance had diminished until 1854 , and is now on the increase, but on projecting the measures it will be seen that this would indicate a motion of one star in a curve convex towards the other. If there are material errors of observation, the real motion of the companion may be rectilinear, or the change in angle and distance may be caused by a slight difference in the proper motions of the stars. Further careful measures, however, are yet required before any safe inference can be made, and more especially in latitudes where the star rises to a greater altitude than in this country. Capt. Jacob's comparafively small distance in 1854 is not supported by the meridian observations at Greenwich, Oxford, and Washington, from which we might conclude, it was nearly one second greater than his result, but meridian observations are not always reliable for such delicate comparisons, and besides it seems hardly probable that so practised and excellent an astrometer as Capt. Jacob would be in error $\mathrm{I}^{\prime \prime}$ in the distance of so easy a star favoured as he was by his positions at Poona and Madras; Secchi also is confirmatory. The statement of Chr. Mayer that the companion was $13^{\prime \prime}: 2$ due S. of the principal star, or on an angle of $180^{\circ}$ (not $360^{\circ}$ as given by Smyth in the "Cycle"), does not assist an explanation.

Nova OpHIUCHI, I848.-This star has been a difficult object for the generality of telescopes during the last few years. In 1856 it had descended to the eleventh magnitude; ten years later it was a faint twelfth, and in $1874-75$ not higher than thirteen in the scale in ordinary use. Herr Julius Schmidt carefully examined the vicinity at Athens in August I867, fixing the positions of the small stars near the variable, which were discernible in the 6-feet refractor of that observatory. These places are here brought up to the beginning of the present year, with the view to facilitate the recognition of the object which became so suddenly conspicuous to the naked eye at the end of April I 848 . The magnitudes are Schmidt's.

$$
\begin{aligned}
& \text { No. of Magui- RA. N P.D. }
\end{aligned}
$$

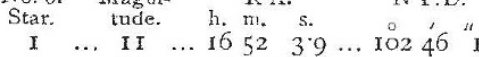

$$
\begin{aligned}
& \begin{array}{lllllllllllll}
2 & \ldots & 13 & \ldots & 1 & 16 & 52 & 3 & 9 & \ldots & 102 & 46 & 1 \\
52 & 28 & 7 & \ldots & 102 & 44 & 4
\end{array} \\
& \text { Nova .. Var. ... I6 } 5233.1 \ldots \text { IO2 } 423\left\{\begin{array}{l}
52 \\
\text { From the first }
\end{array}\right. \\
& \begin{array}{llllllllllllll}
3 & \ldots & \text { II } & \ldots & \text { I6 } & 52 & 55 \% & \ldots & \text { IO2 } & 49 & \text { I } 2
\end{array} \\
& \begin{array}{llllllllllll}
4 & \ldots & \text { II } & \ldots & 16 & 53 & 2 & 5 & \ldots & 102 & 34 & 1
\end{array} \\
& 5 \quad \ldots \text { 10.11 } \ldots 165454198 \ldots 102496
\end{aligned}
$$

The ninth magnitude, Lalande 30853 , R.A. I $876^{\circ}$, I6h. $52 \mathrm{~m}$. I 85 s. N.P.D. $103^{\circ} \mathrm{o}^{\prime} 24^{\prime \prime}$, may be used to identify the variable which it precedes 146 seconds, and is $18^{\prime} 2 \mathrm{I}^{\prime \prime}$ more southerly. Schmidt thought there might be a star 13.14, following the variable 53. or 6s, His stars (1) and (3) had these position-angles and distances, while Nova was still visible without the telescope in 1848 .

$$
\begin{array}{cccccc}
\text { (I) Position } & \ldots & 249^{\circ} 4 & \text { Distance } & \ldots & 475^{\circ} .4 \\
\text { (3) } \quad, & \ldots & 144.5 & ,, & \ldots & 530.8
\end{array}
$$

The star (2) was repeatedly measured in position and distance in 1848 , with the is-inch refractor at Harvard College by the Bonds, with the view to discover if there were appreciable parallax in the variable; it is called a fifteenth magnitude in the Harvard scale, and by a mean of ten nights' measures its position was $212^{\circ} \cdot 1 \mathrm{r}$, and distance II $5^{\prime \prime} \cdot 65$ for $1848^{\circ} 5^{2}$.

STEPHAN'S COMET, I867 (I).-This comet, for which Mr. Searle found an elliptic orbit, period $33^{\circ} 62$ years, or almost precisely that of the comet of the November meteors, and which was shown some years since to make a very near approach to the orbit of the planet Uranus, appears also to pass at a short distance from that of Mars. In heliocentric ecliptical longitude $8 \mathrm{I}^{\circ} 53^{\prime}$, and latitude $+I^{\circ} 5^{\prime}$, with true anomaly, $6^{\circ} 10^{\prime}$, the distance between the two orbits is only $0^{\circ} 0207$, thus affording a similar instance of close approximation to this planet which Dr. Brünow found to take place in the case of De Vico's comet of short-period. It is singular that a comet's orbit should lie so very near to the orbits of two of the planets, in one instance near its perihelion, and in the other not far from aphelion.

THE COMET OF 1698.- In the first orbit of this comet in the last Astronomical Column, the perihelion passage should be dated October. 